\title{
Alterações citológicas do sangue periférico e da medula óssea de cães com cinomose
}

\author{
[Cytological alterations of the bone marrow and peripheral blood of dogs with canine distemper] \\ R.K. Almeida ${ }^{1}$, A.C. Vasconcelos ${ }^{2}$, R.A. Carneiro ${ }^{3}$, P.R.O. Paes $^{3}$, L. Moro ${ }^{2 *}$ \\ ${ }^{1}$ Aluna de pós-graduação - EV-UFMG - Belo Horizonte, MG \\ ${ }^{2}$ Instituto de Ciências Biológicas \\ Av. Antônio Carlos, 6627 \\ 31270-901 - Belo Horizonte, MG \\ ${ }^{3}$ Escola de Veterinária - UFMG - Belo Horizonte, MG
}

\begin{abstract}
RESUMO
Avaliaram-se o mielograma, o hemograma e a ocorrência de apoptose no sangue periférico e na medula óssea de cães com cinomose de ocorrência natural. Foram utilizados 15 cães distribuídos em dois grupos: (a) controle - seis animais clinicamente saudáveis com RT-PCR negativa para o vírus da cinomose canina (CC); (b) infectado - nove animais com manifestações clínicas de CC e RT-PCR positiva. Dos cães com CC, oito $(88,9 \%)$ apresentaram anemia discreta a moderada (hematócrito: $30,6 \%$ ), normocítica (VCM: 67,9fL) e normocrômica (CHCM: $34,1 \mathrm{~g} / \mathrm{dL}$ ). Todos os animais apresentaram contagens médias normais de leucócitos totais $(11600$ células $/ \mu \mathrm{L})$ e neutrófilos segmentados (8802 células $/ \mu \mathrm{L})$. Linfopenia foi observada em cinco animais $(55,6 \%)$ e desvio nuclear dos neutrófilos para a esquerda em oito $(88,9 \%)$. As contagens médias de linfócitos e neutrófilos bastonetes foram, respectivamente, 1054 e 1508 células $/ \mu \mathrm{L}$. No mielograma, todos os animais apresentaram celularidade e relação M:E dentro dos limites de referência. O hemograma e a medula óssea dos cães-controle não apresentaram alteração e não havia células em apoptose no esfregaço sanguíneo desses animais. Nos cães com CC, a média do índice apoptótico foi $0,73 \%$ no esfregaço sanguíneo e $1,87 \%$ na medula óssea. A apoptose, portanto, pode estar envolvida na patogênese das alterações hematológicas observadas na CC.
\end{abstract}

Palavras-chave: cão, cinomose, medula óssea, apoptose, hemograma

\begin{abstract}
The myelogram, the hemogram, and the occurrence of apoptosis in peripheral blood and bone marrow in dogs with canine distemper (CD) of natural occurrence were studied. Fifteen dogs were distributed into two groups: (a) control - six clinically healthy animals with RT-PCR negative for canine distemper virus $(C D V)$; and (b) infected - nine animals showing clinical CD manifestations and RT-PCR positive. The majority of dogs with CD (88.9\%) presented discrete to moderate (hematocrit: $30.6 \%)$, normocytic (MCH: 67.9fL) and normochromic (MCHC: 34.1g/dL) anemia. All animals showed total leukocytes counting $(11,600$ cells/ $\mu L)$ and segmented neutrophils $(8,802$ cells/ $\mu L)$ within the limits of reference. Lymphopenia and left shift neutrophils were observed in 55.6\% and $88.9 \%$ of the dogs, respectively. Additionally, the average counts of lymphocytes and neutrophils were 1,054 and 1,508cells/ $\mu L$, respectively. The myelogram of all animals presented cellularity and M:E relation within the limits of reference. Haemogram and bone marrow of the control dogs had no alteration. Moreover, no apoptotic cells were detected in the smear of the peripheral blood of control animals. On the other side, dogs with $C D$ presented a higher apoptotic index (AI), both in the peripheral blood (AI: 0.73\%) and in the bone marrow (AI: 1.87\%). Therefore, apoptosis may contribute to hematological changes observed in CD.
\end{abstract}

Keywords: dog, canine distemper, bone marrow, apoptosis, hemogram

Recebido em 25 de março de 2009

Aceito em 5 de novembro de 2009

*Autor para correspondência (corresponding author)

E-mail: moro@icb.ufmg.br 


\section{INTRODUÇÃO}

A cinomose canina (CC) é uma doença contagiosa, sistêmica, viral e imunossupressora, aguda ou subaguda, que acarreta manifestações clínicas respiratórias, gastrintestinais e neurológicas. O vírus da cinomose canina (VCC) é um vírus de RNA de fita simples e orientação negativa, possui envelope e, como outros morbilivírus, usa o signaling lymphocyte activation molecule (SLAM)/CD150 como receptor celular, o que explica seu linfotropismo (Tatsuo et al., 2001) que conduz à imunossupressão (Moro, 2001; Moro et al., 2003b)

Após a infecção, o VCC se multiplica em macrófagos do trato respiratório e tonsilas (Appel, 1969). O envolvimento da medula óssea representa uma rota de infecção para outras células circulantes, tais como leucócitos e eritrócitos (McLaughlin et al., 1985). Os principais achados hematológicos observados em cães com CC são: linfopenia, anemia arregenerativa e trombocitopenia (Krakowka et al., 1985). No final da primeira semana após a infecção, os animais podem apresentar discreta neutropenia. Na presença de infecção bacteriana secundária, observa-se neutrofilia (Cornwell et al. 1965).

A apoptose é um tipo de morte celular ativa que depende de energia, síntese (Kerr e Searle, 1972) e degradação proteicas (Grimm e Osborne, 1999). Dentre os estímulos patológicos indutores de apoptose, citam-se alguns vírus, entre os quais o VCC (Moro, 2001; Moro et al., 2003b; Kumagai et al., 2004, Alves et al., 2006). Bunting et al. (1997) relataram que é raro o achado de células apoptóticas no sangue de humanos normais. Por outro lado, células em apoptose são frequentemente encontradas no sangue de pacientes com mielogenose aguda, leucemia linfocítica e com deficiência de vitamina $B_{12}$ (Bunting et al., 1997) e em cães com CC experimental (Moro al., 2003a).

A avaliação da medula óssea (MO) tem-se mostrado uma valiosa técnica diagnóstica para a prática veterinária, informando desordens hematológicas primárias, agentes infecciosos e neoplasias e auxiliando no prognóstico de diversas enfermidades (Grindem et al., 2002).
Até o momento, não há pesquisas direcionadas para as alterações hematológicas e medulares na $\mathrm{CC}$ que enfoquem a ocorrência de apoptose. Os objetivos do presente estudo foram: avaliar as alterações da $\mathrm{MO}$ e do sangue periférico em cães com CC de ocorrência natural e quantificar a ocorrência de apoptose na MO e no sangue de cães com $\mathrm{CC}$ de ocorrência natural.

\section{MATERIAL E MÉTODOS}

O estudo foi realizado com aprovação pelo Comitê de Ética em Experimentação Animal da Universidade Federal de Minas Gerais.

Para o grupo-controle, foram utilizados seis animais saudáveis que permaneceram em quarentena para realização de exames clínicos e laboratoriais, tais como: sorologia para leishmaniose e RT-PCR para CC. Para o grupo infectado, foram utilizados nove animais atendidos no Hospital Veterinário, com manifestações clínicas de CC e RT-PCR positiva para VCC.

O sangue colhido em tubo contendo ácido etilenodiaminotetracético (EDTA) foi submetido à análise automatizada. $\mathrm{O}$ estudo da morfologia das hemácias, contagem diferencial de leucócitos, avaliação de plaquetas e de células em apoptose foi realizado em esfregaços corados pelo método de May-Grunwald-Giemsa (MGG), conforme Carvalho (1983), com identificação de pelo menos 100 células nucleadas. A colheita da MO foi feita na região do esterno, segundo técnica descrita por Lewis e Rebar (1979), e as amostras coradas pelo MGG. Um mínimo de 500 células foi identificado em cada lâmina.

A técnica da RT-PCR foi realizada a partir de $300 \mu 1$ de sangue. As sequências-alvo para seleção dos iniciadores foram obtidas pelo programa BLAST/NCBI (Blast..., 2001), e as análises foram realizadas no programa $P C / G E N E$ 6.6-Intelligenetics/1992. Foram utilizados oligonucleotídeos iniciadores para amplificação de um fragmento de 319 pares de base dentro da região que codifica a proteína do nucleocapsídeo viral, iniciador direto VCC01: [5'-cag cac cgt aca tgg tta ata-3'] e iniciador reverso VCC02: [5'-tag cat aac tcc aga gca atg-3'] e para amplificação de um fragmento de 93 pares de base dentro da região que codifica a proteína $\beta$ actina do cão, um gene housekeeping, para confirmação da 
viabilidade das amostras, com iniciador direto FORBETADOG: [5'-cac ctt cta caa cga gct gcg3'] e iniciador reverso REVBETADOG: [5'-atc ttc tca cgg ttg gec ttg- $\left.3^{\prime}\right]$.

A análise estatística foi realizada utilizando os testes t e SNK para os valores paramétricos e os testes Mann-Whitney e Kruskal-Wallis para os valores não paramétricos.

\section{RESULTADOS E DISCUSSÃO}

Os animais do grupo-controle apresentaram os resultados laboratoriais dentro da faixa de normalidade para a espécie. No grupo infectado, oito animais $(88,9 \%)$ mostraram redução da contagem de hemácias, da concentração de hemoglobina e/ou do hematócrito (Tab. 1), caracterizando anemia. De acordo com o critério proposto por Jain (1993), quatro animais $(44,4 \%)$ apresentavam anemia discreta e quatro $(44,4 \%)$, anemia moderada. Resultados semelhantes foram observados por Krakowka et al. (1985) que relataram ser a anemia o principal achado hematológico da série vermelha em cães com CC. Todos os animais apresentaram índices eritrocitários (volume corpuscular médio concentração de hemoglobina corpuscular média e hemoglobina corpuscular média dentro dos limites de referência, sendo classificados como normocíticos e normocrômicos.

Tabela 1. Valores do hemograma de nove cães infectados pelo vírus da cinomose

\begin{tabular}{cccccccccccc}
\hline & 1 & 2 & 3 & 4 & 5 & 6 & 7 & 8 & 9 & Média & V. Ref. \\
\hline Eritrograma & & & & & & & & & & & \\
Hemácias (x 10 $/ \mu \mathrm{L})$ & 5,4 & 6,0 & 3,8 & 5,0 & 4,4 & 3,6 & 5,0 & 5,2 & 4,0 & 4,71 & $5,5-8,5$ \\
Hemoglobina (g/dL) & 13,1 & 13,7 & 8,4 & 10,3 & 10,2 & 10,2 & 12,2 & 10,9 & 8,7 & 10,86 & $12,0-18,0$ \\
Hematócrito (\%) & 36,2 & 39,2 & 26,4 & 31,2 & 28,5 & 28,5 & 34,7 & 32,8 & 28,1 & 31,73 & $37,0-55,0$ \\
VCM (fL) & 67,0 & 65,0 & 69,0 & 62,3 & 64,6 & 79,4 & 70,1 & 63,0 & 70,4 & 67,87 & $60,0-77,0$ \\
HCM (pg) & 24,3 & 22,9 & 21,9 & 20,6 & 23,1 & 28,4 & 24,6 & 21,0 & 21,8 & 23,18 & $19,5-24,5$ \\
CHCM (g/dL) & 36,2 & 35,0 & 31,6 & 33,0 & 35,8 & 35,8 & 35,2 & 33,0 & 31,0 & 34,07 & $32,0-36,0$ \\
Leucograma & & & & & & & & & & \\
Leucócitos $(\mu \mathrm{L})$ & 13900 & 9600 & 14700 & 12400 & 15900 & 10300 & 6300 & 12400 & 9300 & 11640 & $6000-17000$ \\
Bastonetes $(\mu \mathrm{L})$ & 1112,0 & 4800,0 & 1176,0 & 620,0 & 2703,0 & 618,0 & 504,0 & 0,0 & 2039,0 & 1508 & $0-300$ \\
Segmentados $(\mu \mathrm{L})$ & 10842,0 & 4512,0 & $12201,010664,0$ & 8904,0 & 6283,0 & 4158,0 & 9424,0 & 5747,0 & $8081,673000-11500$ \\
Eosinófilos $(\mu \mathrm{L})$ & 139,0 & 192,0 & 0,0 & 372,0 & 1590,0 & 2060,0 & 378,0 & 620,0 & 0,0 & 594,56 & $100-1200$ \\
Basófilos $(\mu \mathrm{L})$ & 0,0 & 0,0 & 0,0 & 0,0 & 477,0 & 0,0 & 0,0 & 0,0 & 0,0 & 53 & Raros \\
Monócitos $(\mu \mathrm{L})$ & 695,0 & 96,0 & 441,0 & 248,0 & 795,0 & 309,0 & 315,0 & 620,0 & 556,0 & 452,78 & $150-1350$ \\
Linfócitos $(\mu \mathrm{L})$ & 1112,0 & 384,0 & 882,0 & 496,0 & 1431,0 & 1330,0 & 945,0 & 1736,0 & 927,0 & 1027 & $1000-4800$ \\
Plaquetas (x 10 $/ \mu \mathrm{L})$ & 551,0 & 538,0 & 355,0 & 329,0 & 457,0 & 663,0 & 185,0 & 328,0 & 169,0 & 397,22 & $175-500$ \\
Apoptose & 0,80 & 1,60 & 0,40 & 0,00 & 0,00 & 0,00 & 0,00 & 0,80 & 3,00 & 0,73 & 0,00 \\
\hline VCM:volume corpuscular médio, CHCM: concentração de hemoglobina corpuscular, HCM: hemoglobina
\end{tabular}

Segundo Tvedten e Weiss (2000), as anemias discretas geralmente são arregenerativas, podendo ser resultantes de doença inflamatória. Para Waner e Harrus (2000), na doença inflamatória, a liberação de interleucina-1 pelos macrófagos torna o ferro pouco disponível para a produção de hemácias. Adicionalmente, ocorre diminuição da sobrevida dos eritrócitos com aumento da sua destruição pelos macrófagos. Além disso, há diminuição da resposta à anemia devido à baixa produção de eritropoetina, diminuição da resposta da medula óssea à eritropoetina e falta de ferro, culminando com limitação da eritropoiese.

No leucograma, todos os animais apresentaram contagens de leucócitos totais e de neutrófilos segmentados dentro dos valores de referência. Apesar de não haver alterações na contagem de neutrófilos maduros, oito animais $(88,9 \%)$ apresentaram aumento da contagem de neutrófilos bastonetes, o que caracteriza desvio nuclear dos neutrófilos para a esquerda (DNNE) do tipo regenerativo, que, segundo Stockham e Scott (2002), pode caracterizar resposta neutrofílica à inflamação. A média da contagem de linfócitos ficou próxima ao limite inferior de normalidade, sendo que cinco animais $(55,6 \%)$ apresentaram linfopenia. No exame das plaquetas, apenas um animal $(11,1 \%)$ apresentou contagem de plaquetas discretamente abaixo do limite de referência (Tab. 1). Este resultado pode estar relacionado com a ação do vírus, causando 
bicitopenia, já que o animal também estava anêmico.

Outros trabalhos descreveram linfopenia em cães com CC (Moro, 2001; Schobesberger et al., 2005). Segundo Jain (1993), a linfopenia está relacionada com atrofia e necrose de tecido linfoide produzida pela ação do vírus. A linfopenia acompanhada de DNNE regenerativo, observada neste trabalho, é compatível com leucograma de reação inflamatória.

A literatura é escassa quanto aos efeitos do VCC sobre a MO, não havendo relatos sobre o comportamento do mielograma na $\mathrm{CC}$. $\mathrm{O}$ mielograma de todos os animais apresentou celularidade e relação mieloide:eritroide (M:E) compatíveis com as de animais saudáveis (Tab. 2). $\mathrm{Na}$ série eritroide, em nenhum animal foi observada alteração quanto à celularidade, maturação e morfologia, quando comparado com o grupo-controle e com os valores propostos por Harvey (2002). Na série mieloide, as células iniciais da linhagem precursora de neutrófilos (mieloblastos, promielócitos, mielócitos e metamielócitos) apresentaram valores reduzidos, ao passo que os bastonetes e os neutrófilos apresentaram valores aumentados e semelhantes, respectivamente, àqueles propostos por Harvey (2002). Na maior parte dos casos de DNNE, o esgotamento dos neutrófilos segmentados da medula óssea determina a liberação de maior concentração de neutrófilos jovens, tais como os neutrófilos bastonetes. A observação do DNNE com o estoque de neutrófilos segmentados normal indica que na $\mathrm{CC}$ há uma alteração medular que aumenta a liberação de neutrófilos jovens.

Tabela 2. Valores do mielograma de nove cães infectados pelo vírus da cinomose

\begin{tabular}{|c|c|c|c|c|c|c|c|c|c|c|c|}
\hline \multirow{2}{*}{ Celularidade } & 1 & 2 & 3 & 4 & 5 & 6 & 7 & 8 & 9 & Média & \multirow{2}{*}{ Val. Ref. } \\
\hline & $60 \%$ & $40 \%$ & $50 \%$ & $60 \%$ & $60 \%$ & $50 \%$ & $40 \%$ & $40 \%$ & $60 \%$ & $51 \%$ & \\
\hline \multicolumn{12}{|l|}{ Tipo celular (\%) } \\
\hline rubriblastos & 0,00 & 0,00 & 0,31 & 0,70 & 0,00 & 0,00 & 0,70 & 0,93 & 0,73 & 0,37 & $0,20-1,10$ \\
\hline prórubrícitos & 3,20 & 5,08 & 2,80 & 2,34 & 3,00 & 0,82 & 2,20 & 2,80 & 3,88 & 2,9 & $0,90-2,20$ \\
\hline rubrícitos & 33,73 & 16,10 & 20,25 & 43,93 & 21,25 & 25,20 & 34,32 & 33,02 & 43,45 & 30,14 & $19,20-35,10$ \\
\hline metarubrícitos & 13,66 & 9,32 & 13,06 & 12,14 & 12,05 & 9,50 & 15,30 & 8,37 & 11,17 & 11,62 & $9,20-16,40$ \\
\hline Linfoblastos & 0,10 & 0,00 & 0,12 & 0,00 & 0,15 & 0,10 & 0,04 & 0,08 & 0,15 & 0,08 & 0,0 \\
\hline Linfócitos & 2,40 & 4,23 & 2,32 & 1,40 & 1,88 & 2,07 & 2,02 & 2,20 & 2,18 & 2,3 & $1,70-4,90$ \\
\hline Plasmócitos & 0,80 & 0,00 & 0,33 & 0,47 & 0,90 & 0,83 & 1,00 & 0,00 & 0,00 & 0,48 & $0,60-2,40$ \\
\hline $\begin{array}{l}\text { Macrófagos e } \\
\text { monócitos }\end{array}$ & 2,41 & 1,69 & 1,32 & 1,40 & 0,45 & 0,83 & 1,45 & 0,00 & 0,48 & 1,11 & $0,40-2,40$ \\
\hline Hematogônias & 2,30 & 1,54 & 0,93 & 0,48 & 1,90 & 1,01 & 3,13 & 0,52 & 0,77 & 1,4 & 0,0 \\
\hline $\begin{array}{l}\text { Células } \\
\text { reticuloendoteliais }\end{array}$ & 5,75 & 1,35 & 0,00 & 1,77 & 2,47 & 2,23 & 1,42 & 2,42 & 0,00 & 1,93 & - \\
\hline Apoptose & 1,53 & 0,77 & 1,12 & 0,96 & 1,14 & 0,41 & 3,99 & 2,07 & 4,80 & 1,87 & 0,0 \\
\hline Mitoses & 0,38 & 0,19 & 0,19 & 0,32 & 0,76 & 0,61 & 0,57 & 1,04 & 3,64 & 0,86 & - \\
\hline Mieloblastos & 0,00 & 0,00 & 0,00 & 0,00 & 0,00 & 0,00 & 0,00 & 0,00 & 0,00 & 0,00 & $0,40-1,10$ \\
\hline Promielócitos & 0,40 & 1,69 & 0,31 & 0,48 & 1,05 & 0,41 & 0,55 & 1,40 & 1,70 & 0,89 & $1,10-2,30$ \\
\hline Mielócitos & 4,21 & 2,54 & 0,93 & 0,93 & 2,25 & 0,82 & 1,03 & 5,58 & 1,94 & 2,25 & $3,10-6,10$ \\
\hline Metamielócito & 3,61 & 2,54 & 4,36 & 6,54 & 2,58 & 1,65 & 3,54 & 6,51 & 2,43 & 3,75 & $5,30-8,80$ \\
\hline Bastonetes & 16,06 & 11,00 & 20,25 & 10,98 & 20,25 & 6,61 & 15,49 & 21,80 & 12,14 & 14,95 & $12,70-17,20$ \\
\hline Segmentados & 18,47 & 42,37 & 33,02 & 15,88 & 33,00 & 49,38 & 21,23 & 18,12 & 19,66 & 27,9 & $13,80-24,20$ \\
\hline Eosinofilos & 1,05 & 3,39 & 1,25 & 1,09 & 1,34 & 1,65 & 1,04 & 1,04 & 0,00 & 1,32 & $1,80-5,60$ \\
\hline Basófilos & 0,00 & 0,00 & 0,00 & 0,00 & 0,00 & 0,00 & 0,00 & 0,00 & 0,00 & 0,0 & $0,0-0,80$ \\
\hline Relação M/E & 0,85 & 2,00 & 1,62 & 0,59 & 1,63 & 1,66 & 0,80 & 1,18 & 0,64 & 1,22 & $0,90-1,76$ \\
\hline
\end{tabular}

No esfregaço sanguíneo dos cães do grupocontrole, não foram observadas células em apoptose. No grupo dos animais infectados, este achado foi constante. Estes resultados são semelhantes aos de Bunting et al. (1997), que descreveram a apoptose como rara no esfregaço sanguíneo de pessoas sadias, e frequente nos pacientes humanos com algum tipo de alteração. 
A presença de células em apoptose no sangue periférico de animais com CC foi anteriormente descrita (Moro, 2001; Moro et al., 2003a, b). Entretanto, Cornwell et al. (1965) já haviam observado a presença de células com sinais de degeneração e picnose em animais experimentalmente infectados pelo VCC. Pela descrição dos autores, é provável que essas células em degeneração fossem, na verdade, células em apoptose. Sabe-se que o VCC induz apoptose em células linfoides (Moro et al., 2003b; Kumagai et al., 2004; Alves et al., 2006) tanto direta quanto indiretamente (Kumagai et al., 2004). Ao utilizar-se o CD150 como receptor celular (Tatsuo et al., 2001), o vírus do sarampo inibe a diferenciação terminal de células dendríticas e as torna mais susceptíveis à apoptose (Hahm et al., 2004). É sabido que o CD150 modula a apoptose mediada pelo CD95 em linhagens de linfócitos T e B (Mikhalap et al., 1999). Portanto, é possível que esses mesmos mecanismos estejam envolvidos na apoptose induzida pelo VCC.

O índice apoptótico (IA), encontrado na MO dos animais infectados com CC (Fig. 1), foi maior que aquele dos animais do grupo-controle e, também, maior que o IA do sangue periférico. Além disso, estes dados complementam relatos anteriores que mostraram valores maiores de IA nos linfonodos retrofaríngeos (Moro, 2001; Moro et al., 2003b) e no timo de cães com CC (Alves et al., 2006), tanto em infecção natural quanto experimental. Estudos adicionais devem ser feitos no sentido de se utilizar os IAs do sangue periférico e da medula óssea para monitorar o curso da CC e determinar o prognóstico.
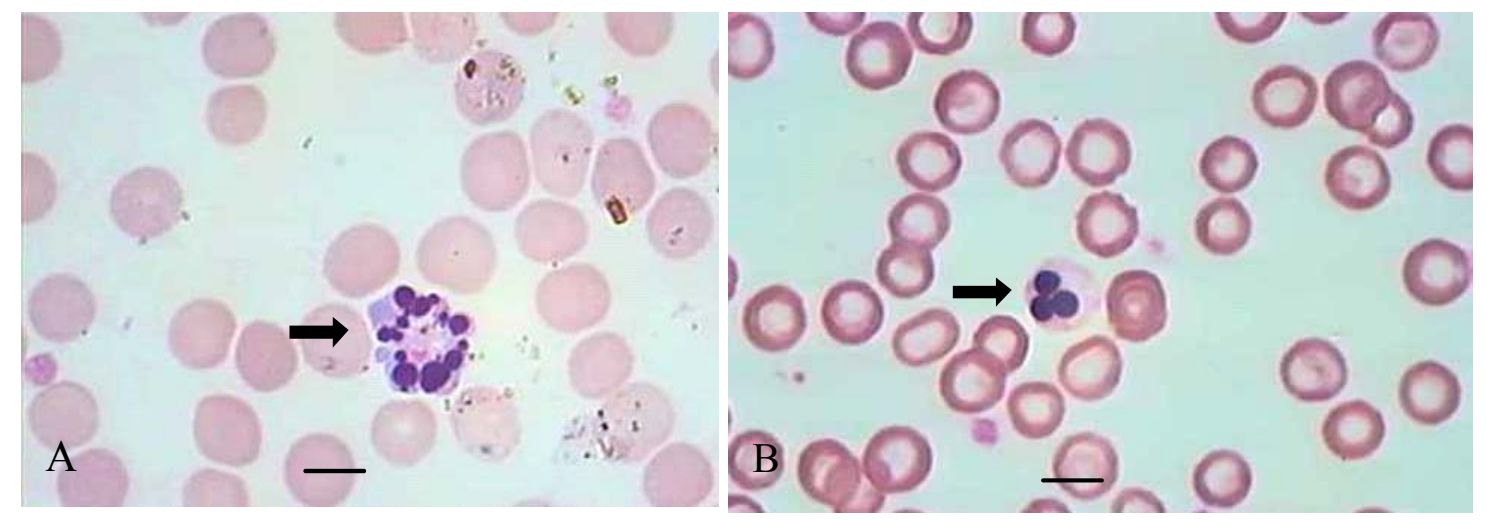

Figura 1. Micrografias de esfregaço de medula óssea (A e B) de cães com cinomose canina. Setas Células com características de apoptose - citoplasma retraído e fortemente corado e núcleo fragmentado. Em (A) notar digitações citoplasmáticas. Em (B) notar fragmentação nuclear. (MGG; Barra $=6 \mu \mathrm{m})$.

\section{CONCLUSÕES}

As alterações hematológicas mais relevantes da $\mathrm{CC}$ incluem: anemia normocítica normocrômica de discreta a moderada; linfopenia; desvio nuclear dos neutrófilos para a esquerda no sangue periférico e elevado índice apoptótico no sangue e medula óssea.

\section{AGRADECIMENTOS}

À FAPEMIG, pelo financiamento, ao CNPq, pela bolsa concedida e ao Professor Almir de Sousa Martins e Helen Lima del Puerto, pela execução da RT-PCR.

\section{REFERÊNCIAS BIBLIOGRÁFICAS}

ALVES, C.M.; VASCONCELOS, A.C.; MARTINS, A.S. et al. Morphometrical analysis of the thymus of puppies infected with the Snyder Hill Strain of canine distemper virus. Arq. Bras. Med. Vet. Zootec., v.58, p.472-479, 2006.

APPEL, M.J. Pathogenesis of canine distemper. Am. J. Vet. Res., v.30, p.1167-1182, 1969.

BLAST finds regions of similarity between biological sequences. Disponível em: http://www.ncbi.nlm.nih.gov/blast/blast.cgi. Acessado em: 10 maio 2001. 
BUNTING, R.W.; SELIG, M.K.; DICKERSIN, G.R. Apoptotic cells in peripheral blood from patients with low serum cobalamin. $J$. Submicrosc. Cytol. Pathol., v.29, p.223-227, 1997.

CARVALHO, W.F. (Ed.). Técnicas médicas de hematologia e imuno-hematologia. 3.ed. Belo Horizonte: Cooperativa Editora e de Cultura Médica, 1983. 270p.

CORNWELL, H.J.C.; VANTSIS; J.T; CAMPBELL, R.S.F. et al. Studies in experimental canine distemper. II. Virology, inclusion body studies and haematology $J$. Comp. Pathol., v.75, p.19-35, 1965.

GRIMM, L.M.; OSBORNE, B.A. Apoptosis and proteasome. Results Probl. Cell Differ., v.23, p.209-228, 1999.

GRINDEM, C.B.; NEEL, J.A.; JUOPPERI, T.A. Cytology of bone marrow. Vet. Clin. Small Anim., v.32, p.1313-1374, 2002.

HAHM, B.; ARBOUR, N.; OLDSTONE, B.A. Measles virus interacts with human SLAM receptor on dendritic cells to cause immunosuppression. Virology, v.323, p.292-302, 2004.

HARVEY, J.C. (Ed.). Atlas of veterinary hematology, blood and bone marrow of domestic animals. Philadelphia: W.B. Saunders, 2002. 228p.

JAIN, N.C. (Ed.). Essentials of veterinary hematology. Philadelphia: Lea \& Febiger, 1993. $417 \mathrm{p}$.

KERR, J.F.R.; SEARLE, J.A. A suggested explanation for the paradoxically slow growth rate of basal cell carcinomas that contain numerous mitotic figure. J. Pathol., v.107, p.4144, 1972.

KRAKOWKA, S.; AXTHELM, M.K.; JOHNSON, G.C. Canine distemper virus. In: OLSEN, R.G., KRAKOWKA, S., BLAKESLEE, J.R. (Ed.). Comparative pathobiology of viral diseases. Boca Raton: CRC, 1985. p.137-164.

KUMAGAI, K; YANMAGUCHI, R.; UCHIDA, $\mathrm{K}$. et al. Lymphoid apoptosis in acute canine distemper. J. Vet. Med. Sci., v.66, p.175-181, 2004.
LEWIS, H.B.; REBAR, A.H. (Ed.) Bone marrow evaluation in veterinary practice. Ralston: Purina Company, 1979, 73p.

McLAUGHLIN， B.G.; ADAMS， P.S.; CORNELL, W.D. et al. Canine distemper viral inclusions in blood cells of four vaccinated dogs. Can. Vet. J., v.26, p.368-372, 1985.

MIKHALAP, S.V.; SHLAPATSKA, L.M.; BERDOVA, A.G. et al. CDw150 associates with Src-homology 2-containing inositol phosphatase and modulates CD95-mediated apoptosis. $J$. Immunol., v.162, p.5719-5727, 1999.

MORO, L. Apoptose na patogenia da cinomose canina. 2001. 213f. Tese (Doutorado em Patologia Geral) - Universidade Federal de Minas Gerais, Faculdade de Medicina, Belo Horizonte.

MORO, L.; ALVES, C.M.; SANTOS, F.G.A. et al. Ocorrência de apoptose em leucócitos no esfregaço de sangue periférico e em sincícios na infecção in vivo pelo vírus da cinomose canina. Arq. Bras. Med. Vet. Zootec., v.55, p.110-112, 2003a.

MORO, L.; MARTINS, A.S.; ALVES, C.M. et al. Apoptosis in canine distemper. Arch. Virol., v.148, p.153-164, 2003b.

SCHOBESBERGER, M., SUMMERFIELD, A., DOHERR, M.G. et al. Canine distemper virusinduced depletion of uninfected lymphocytes is associated with apoptosis. Vet. Immunol. Immunopathol., v.104, p.33-44, 2005.

STOCKHAM, S.L.; SCOTT, M.A. Fundamentals of veterinary clinical pathology, Blackwell: Iowa, 2002. 610p.

TATSUO, H.; ONO, N.; YANAGI, Y. Morbilliviruses use signaling lymphocyte activation molecules (CD150) as cellular receptor. J. Virol., v.75, p.5842-5850, 2001.

TVEDTEN, H.; WEISS, D. Classification and laboratory evaluation of anemia In: FELDMAN, B.F.; ZINKL, J.G.; JAIN, N.C. et al. (Ed.). Schalm's veterinary hematology. 5.ed. Philadelphia: Lippincott Williams \& Wilkins, 2000. 1344p.

WANER, T.; HARRUS Anemia of inflammatory disease. In: FELDMAN, B.F.; ZINKL, J.G.; JAIN, N.C. et al. (Eds.). Schalm's veterinary hematology. 5.ed. Philadelphia: Lippincott Williams \& Wilkins, 2000. 1344p. 